\title{
Sistem Usaha pada Benih Ikan Kerapu untuk Mencukupi Kebutuhan Budidaya
}

\author{
[The Grouper Fries Fish Trader Business System \\ to Support Demand for Aquaculture]
}

\section{Suko Ismi}

Balai Besar Riset Budidaya Laut dan Penyuluhan Perikanan Gondol-Bali

\begin{abstract}
Abstrak
Tujuan penelitian adalah untuk megetahui sistem usaha benih ikan kerapu dalam rangka memenuhi kebutuhan budidaya. Penelitian dilakukan pada bulan Februari sampai dengan Nopember 2018 di Kabupaten Buleleng-Bali. Responden penelitian adalah sepuluh pengusaha benih ikan kerapu yang berada di Kecamatan Gerokgak. Data dikumpulkan dengan metode survei, pengamatan dan wawancara dan dianalisis secara deskriptif. Hasil penelitian menggambarkan bahwa benih ikan kerapu yang dipasarkan sesuai permintaan pasar yaitu cantang dan cantik. Sistem usaha benih yang dilakukan ada beberapa cara yaitu hasil pembenihan sendiri dari ukuran $\pm 2,7 \mathrm{~cm}$ benih langsung dijual atau benih didederkan hingga ukuran tertentu sesuai permintaan, membeli benih ukuran $\pm 2,7 \mathrm{~cm}$ kemudian dipelihara pada pendederan hingga ukuran sesuai permintaaan dan membeli sesuai ukuran permintaan dan langsung dikirim. Hasil analisis usaha menunjukkan bahwa $\mathrm{R} / \mathrm{C}$ rasio $>1,0$. Tujuan pemasaran adalah domestik dan ekspor dengan harga benih berfluktuasi tergantung waktu, mulai ukuran \pm $4 \mathrm{~cm}$ harga sesuai dengan panjang total. Kendala kelangsungan hidup yang rendah akibat cuaca dan transportasi.
\end{abstract}

Kata kunci: benih; ikan kerapu; kebutuhan; sistem usaha

\begin{abstract}
The purpose of this research is to get information about the business system of grouper fries for supportig demand of aquaculture. The study was conducted in Gerokgak District, Buleleng Regency to ten grouper fries businessman on February - November 2018. The collection of primary and secondary data is obtained by direct observation and literature study data were analyzed descriptively. The results of the research of grouper fries that were marketed according to market demand were cantang and cantik. There were several ways that traders get grouper fries, namely their own production from $\pm 2,7 \mathrm{~cm}$ of fries sold directly or saved for in nursery until fries match to size the request, buy seeds measuring $\pm 2,7 \mathrm{~cm}$ then saved for in the nursery until they are of the appropriate size for demand and directly buy according to the size of the requested. The business analysis of was still profitable with an $\mathrm{R} / \mathrm{C}$ ratio $>1,0$. The fries market for domestic and export with price fluctuations depending on the season, constraints on the low survival in nurseries and transportation.
\end{abstract}

Keywords : business; demand; grouper fish, fries

Penulis Korespondensi

Suko Ismi | sukoismi@yahoo.com 


\section{PENDAHULUAN}

Ikan kerapu merupakan salah satu komoditas perikanan yang mempunyai harga mahal. Saat ini budidaya ikan kerapu telah berkembang pesat baik di Indonesia maupun di luar negeri. Jenisjenis ikan kerapu yang mempunyai harga yang mahal di pasaran antara lain genus Epinephelus, Cromileptes dan Plectropomus (Rimmer, Bride, dan William 2004). Saat ini kerapu hybrid cantang dan cantik juga telah berkembang dan sangat diminati pasar.

Ikan kerapu cantang adalah hasil hibridisasi antara betina kerapu macan (Epinephelus fuscogutatus) dan jantan kerapu kertang (Epinephelus lanciolatus). Kerapu ini mempunyai pertumbuhan yang cepat seperti ikan kerapu kertang (Ismi dan Asih 2011a), dengan sifat kanibalisme lebih rendah dibandingkan ikan kerapu macan (Ismi dan Asih 2011b).

Kerapu cantik merupakan hibrida antara betina kerapu macan (Epinephelus fuscoguttatus) dan jantan kerapu batik (Epinephelus microdon). Ikan kerapu batik pertumbuhannya lambat dan tahan terhadap penyakit, sampai saat ini masih susah untuk dibenihkan tetapi banyak diminati untuk konsumsi karena mempunyai rasa yang enak (Giri 2001).

Pembenihan ikan kerapu saat ini sudah berkembang dari usaha kecil hingga besar untuk memenuhi kebutuhan benih pada budidaya dan telah menjadi usaha yang menguntungkan di masyarakat serta dapat menyerap banyak tenaga kerja (Siar, Johnston, dan Sim 2001). Selain untuk mencukupi kebutuhan budidaya laut di Indonesia, benih ikan kerapu yang diproduksi juga dikirim ke Singapura, Malaysia, Brunei, Vietnam, Thailand, Taiwan, Hong Kong dan China (Heerin 2002; Ismi 2010). Oleh karena itu, penelitian ini bertujuan untuk mengetahui sistem usaha benih ikan kerapu dalam rangka memenuhi kebutuhan budidaya.

\section{BAHAN DAN METODE}

Penelitian dilakukan pada sepuluh pengusaha benih ikan di Kecamatan Gerokgak, Kabupaten Buleleng Bali, dimulai pada bulan Februari sampai dengan Nopember 2018. Kriteria usaha yang dipilih untuk penelitian ini adalah yang terus menerus aktif sepanjang tahun menyediakan benih ikan kerapu. Data primer dikumpulkan dengan survei, pengamatan dan wawancara langsung setiap bulan di lapangan. Data sekunder sebagai data pelengkap diperoleh melalui informasi-informasi dari instansi terkait, publikasi dan pustaka lainnya yang mendukung penelitian ini, Data yang dikumpulkan diantaranya : cara memperoleh benih, sarana pemeliharaan benih, analisis usaha, pemasaran, dan 
kendala, data yang dikumpulkan dianalisis secara diskriptif.

Analisis usaha dilakukan dengan menghitung dari jumlah modal operasional yang dikeluarkan dan penerimaan, tanpa menghitung biaya investasi tanah dan bangunan. Keuntungan usaha dihitung dalam satu siklus peroduksi dengan menggunakan rumus Return Cost Rasio (R/C) (Soekartawi 1991, 2001) . R/C adalah perbandingan antara total penerimaan dengan biaya operasional yang dikeluarkan selama proses produksi.

$$
\mathrm{R} / \mathrm{C} \text { Ratio }=\frac{\text { Total penerimaan }}{\text { Biaya Operasional }}
$$

Kriteria usaha yang digunakan adalah: $\mathrm{R} / \mathrm{C}>1$, maka usaha untung

$\mathrm{R} / \mathrm{C}<1$, maka usaha rugi

$\mathrm{R} / \mathrm{C}=1$, maka usaha impas

\section{HASIL DAN PEMBAHASAN}

Hasil pengamatan dari sepuluh pengusaha benih ikan kerapu yang berada di Kecamatan Gerokgak, menunjukkan bahwa benih ikan kerapu yang diminati untuk diperdagangkan sesuai permintaan adalah kerapu cantang dan kerapu cantik. Benih dibeli dari Bali dan Situbondo. Data selengkapnya disajikan pada Tabel 1.

\section{Asal benih}

Dari data Tabel 1. :

Satu pengusaha : benih diperoleh dari hasil pembenihan sendiri setelah ukuran $\pm 2,7 \mathrm{~cm}$

dijual atau

dipelihara di

pendederan hingga

ukuran sesuai

permintaaan.

Dua pengusaha : hanya membeli dari

ukuran $\pm 2,7 \mathrm{~cm}$

kemudian dipelihara

di pendederan

hingga ukuran

sesuai permintaaan.

Tiga pengusaha : benih diperoleh dari hasil pembenihan sendiri setelah ukuran $\pm 2,7 \mathrm{~cm}$

dijual atau dipelihara di pendederan. membeli dari ukuran $\pm 2,7 \mathrm{~cm}$ kemudian dipelihara di pendederan hingga ukuran sesuai permintaaan. 
Tabel 1. Data Hasil Survey dari Sepuluh Usaha Benih Ikan Kerapu di Kecamatan Gerokgak

\begin{tabular}{|c|c|c|c|c|c|c|}
\hline No. & Asal benih & Status benih & Pemasaran & Jenis ikan & $\begin{array}{c}\text { ljin } \\
\text { ekspor }\end{array}$ & Kendala \\
\hline \multirow[b]{2}{*}{1} & Hasil benih sendiri & mulai $2,7 \mathrm{~cm}$ & Domestik & \multirow{2}{*}{$\begin{array}{l}\text { kerapu } \\
\text { cantang }\end{array}$} & \multirow[t]{2}{*}{$\begin{array}{l}\text { Tidak } \\
\text { ada }\end{array}$} & $\begin{array}{l}\text { kualitas } \\
\text { telur }\end{array}$ \\
\hline & $\begin{array}{l}\text { Beli ukuran } 2,7 \\
\mathrm{~cm}\end{array}$ & $\begin{array}{l}\text { pendederan sampai } \\
\text { ukuran tertentu }\end{array}$ & domestik & & & Penyakit \\
\hline \multirow{2}{*}{2} & $\begin{array}{l}\text { Beli ukuran 2,7 } \\
\mathrm{cm}\end{array}$ & $\begin{array}{l}\text { pendederan sampai } \\
\text { ukuran tertentu }\end{array}$ & $\begin{array}{l}\text { Domestik } \\
\text { dan ekspor }\end{array}$ & $\begin{array}{l}\text { kerapu } \\
\text { cantang }\end{array}$ & \multirow[t]{2}{*}{ Ada } & Penyakit \\
\hline & $\begin{array}{l}\text { Beli ukuran } \\
\text { permintaan }\end{array}$ & langsung dikirim & $\begin{array}{l}\text { domestik } \\
\text { dan ekspor }\end{array}$ & $\begin{array}{l}\text { kerapu } \\
\text { cantik }\end{array}$ & & $\begin{array}{l}\text { Transportas } \\
\text { i }\end{array}$ \\
\hline \multirow[b]{2}{*}{3} & Hasil benih sendiri & mulai 2,7 cm & domestik & \multirow[t]{2}{*}{$\begin{array}{l}\text { kerapu } \\
\text { cantang }\end{array}$} & \multirow[t]{2}{*}{$\begin{array}{l}\text { tidak } \\
\text { ada }\end{array}$} & $\begin{array}{l}\text { kualitas } \\
\text { telur }\end{array}$ \\
\hline & $\begin{array}{l}\text { Beli ukuran 2,7 } \\
\mathrm{cm}\end{array}$ & $\begin{array}{l}\text { pendederan sampai } \\
\text { ukuran tertentu }\end{array}$ & Domestik & & & Penyakit \\
\hline \multirow{2}{*}{4} & Hasil benih sendiri & sampai 2,7 cm & domestik & \multirow[t]{2}{*}{$\begin{array}{l}\text { kerapu } \\
\text { cantang }\end{array}$} & \multirow[t]{2}{*}{ ada } & $\begin{array}{l}\text { kualitas } \\
\text { telur }\end{array}$ \\
\hline & & $\begin{array}{l}\text { pendederan sampai } \\
\text { ukuran tertentu }\end{array}$ & $\begin{array}{l}\text { domestik } \\
\text { dan ekspor }\end{array}$ & & & Penyakit \\
\hline 5 & $\begin{array}{l}\text { Beli ukuran } 2,7 \\
\mathrm{~cm}\end{array}$ & $\begin{array}{l}\text { pendederan sampai } \\
\text { ukuran tertentu }\end{array}$ & domestik & $\begin{array}{l}\text { kerapu } \\
\text { cantang }\end{array}$ & $\begin{array}{l}\text { tidak } \\
\text { ada }\end{array}$ & Penyakit \\
\hline 6 & $\begin{array}{l}\text { Beli ukuran } 2,7 \\
\mathrm{~cm}\end{array}$ & $\begin{array}{l}\text { pendederan sampai } \\
\text { ukuran tertentu }\end{array}$ & domestik & $\begin{array}{l}\text { kerapu } \\
\text { cantang }\end{array}$ & $\begin{array}{l}\text { tidak } \\
\text { ada }\end{array}$ & Penyakit \\
\hline \multirow{3}{*}{7} & Hasil benih sendiri & sampai $2,7 \mathrm{~cm}$ & domestik & \multirow{3}{*}{$\begin{array}{l}\text { kerapu } \\
\text { cantangker } \\
\text { apu cantik }\end{array}$} & \multirow[t]{3}{*}{ ada } & $\begin{array}{l}\text { kualitas } \\
\text { telur }\end{array}$ \\
\hline & $\begin{array}{l}\text { Beli ukuran } 2,7 \\
\mathrm{~cm}\end{array}$ & $\begin{array}{l}\text { pendederan sampai } \\
\text { ukuran tertentu }\end{array}$ & $\begin{array}{l}\text { domestik } \\
\text { dan ekspor }\end{array}$ & & & Penyakit \\
\hline & $\begin{array}{l}\text { Beli ukuran } \\
\text { permintaan }\end{array}$ & langsung di kirim & $\begin{array}{l}\text { domestik } \\
\text { dan ekspor }\end{array}$ & & & $\begin{array}{l}\text { Transportas } \\
\text { i }\end{array}$ \\
\hline \multirow{3}{*}{8} & Hasil benih sendiri & mulai $2,7 \mathrm{~cm}$ & domestik & \multirow{3}{*}{$\begin{array}{l}\text { kerapu } \\
\text { cantangker } \\
\text { apu cantik }\end{array}$} & \multirow[t]{3}{*}{ ada } & Penyakit \\
\hline & $\begin{array}{l}\text { Beli ukuran 2,7 } \\
\mathrm{cm}\end{array}$ & $\begin{array}{l}\text { pendederan sampai } \\
\text { ukuran tertentu }\end{array}$ & $\begin{array}{l}\text { domestik } \\
\text { dan ekspor }\end{array}$ & & & \\
\hline & $\begin{array}{l}\text { Beli ukuran } \\
\text { permintaan }\end{array}$ & langsung di kirim & $\begin{array}{l}\text { domestik } \\
\text { dan ekspor }\end{array}$ & & & $\begin{array}{l}\text { Transportas } \\
\mathrm{i}\end{array}$ \\
\hline \multirow{3}{*}{9} & Hasil benih sendiri & sampai $2,7 \mathrm{~cm}$ & $\begin{array}{l}\text { domestik } \\
\text { dan ekspor }\end{array}$ & \multirow[t]{3}{*}{$\begin{array}{l}\text { kerapu } \\
\text { cantang }\end{array}$} & \multirow[t]{3}{*}{ ada } & $\begin{array}{l}\text { kualitas } \\
\text { telur }\end{array}$ \\
\hline & $\begin{array}{l}\text { Beli ukuran } 2,7 \\
\mathrm{~cm}\end{array}$ & $\begin{array}{l}\text { pendederan sampai } \\
\text { ukuran tertentu }\end{array}$ & $\begin{array}{l}\text { domestik } \\
\text { dan ekspor }\end{array}$ & & & Penyakit \\
\hline & $\begin{array}{l}\text { Beli ukuran } \\
\text { permintaan }\end{array}$ & langsung di kirim & $\begin{array}{l}\text { domestik } \\
\text { dan ekspor }\end{array}$ & & & $\begin{array}{l}\text { Transportas } \\
\mathrm{i}\end{array}$ \\
\hline \multirow{3}{*}{10} & Hasil benih sendiri & mulai $2,7 \mathrm{~cm}$ & $\begin{array}{l}\text { domestik } \\
\text { dan ekspor }\end{array}$ & \multirow{3}{*}{$\begin{array}{l}\text { kerapu } \\
\text { cantangker } \\
\text { apu cantik }\end{array}$} & \multirow[t]{3}{*}{ ada } & $\begin{array}{l}\text { kualitas } \\
\text { telur }\end{array}$ \\
\hline & $\begin{array}{l}\text { Beli ukuran 2,7 } \\
\mathrm{cm}\end{array}$ & $\begin{array}{l}\text { pendederan sampai } \\
\text { ukuran tertentu }\end{array}$ & $\begin{array}{l}\text { domestik } \\
\text { dan ekspor }\end{array}$ & & & Penyakit \\
\hline & $\begin{array}{l}\text { Beli ukuran } \\
\text { permintaan }\end{array}$ & langsung di kirim & $\begin{array}{l}\text { domestik } \\
\text { dan ekspor }\end{array}$ & & & $\begin{array}{l}\text { Transportas } \\
\mathrm{i}\end{array}$ \\
\hline
\end{tabular}

Empat pengusaha : benih dari hasil

pembenihan sendiri,

dari ukuran $\pm 2,7$

$\mathrm{cm}$ benih langsung

dijual atau benih

didederkan hingga

ukuran tertentu sesuai permintaan.

membeli ukuran \pm

2,7 cm kemudian

dipelihara di

pendederan hingga

ukuran sesuai

permintaaan. 
membeli sesuai

ukuran permintaan

dan langsung

dikirim.

\section{Sarana pemeliharaan benih}

Sarana pemeliharaan yang digunakan oleh sepuluh pengusaha tersebut rata-rata sama, baik pada usaha pembenihan ataupun pada pendederan. Sarana pembenihan terdiri dari bak untuk pemeliharaan larva, bak untuk pakan alami fitoplankton (Nannochloropsis sp.) dan zooplankton dari jenis rotifera (Brachionus sp.). Tangki terbuat dari semen dengan volume 10-16 $\mathrm{m}^{3}$, ruangan tertutup, atap menggunakan fiber transparan (untuk mempertahankan suhu) dan di atas bak larva ditutup menggunakan plastik, atap dibawah fiber diberi shelter yang ketebalannya diatur sesuai dengan intensitas cahaya yang dikendaki. (Ismi, Asih, dan Kusumawati 2013). Cara pembenihan mengacu pada cara pembenihan ikan yang baik (KKP 2008) dengan manajemen pemeliharaan larva mengikuti pada panduan yag telah ada (Sugama et al. 2012)

Tempat kultur pakan alami terbuka dan terkena matahari langsung, bak untuk kultur Nannochloropsis sp. terdiri dari beberapa bak volume berukuran 10 $40 \mathrm{~m}^{3}$ dan untuk kultur rorifera menggunakan beberapa bak dengan volume $6-10 \mathrm{~m}^{3}$. Jumlah dan volume bak kultur Nanochloropsis sp. lebih banyak dari jumlah bak untuk rotifer pada umumnya dengan perbandingan 3:1.

Sarana pendederan terdiri dari bak-bak beton yang jumlahya disesuaikan dengan kebutuhan. Ratarata volume bak adalah $10 \mathrm{~m}^{3}$ dengan sistem air mengalir. Bak ditempatkan pada ruangan yang diberi atap, agar tidak terkena sinar matahari langsung yang dapat mengakibatkan cepat kotor/tumbuh lumut (Ismi, Sutarmat, et al. 2012)

Semua tangki pada pembenihan daan pendederan dilengkapi dengan aerasi untuk suplai oksigen yang berasal dari blower agar diperoleh air laut yang bersih dari kotoran dan lumpur. Air laut yang akan dipergunakan disaring dengan filter pasir. Filter pasir terbuat dari bak semen yang posisinya lebih tinggi dari bak pemeliharaan yang lain sehingga air laut dari filter dapat mengalir ke bak yang lain mengikuti gravitasi. Pada bagian dalam bak filter dari arah dasar bawah ke atas, dipasang batu kali, koral dan pasir. Air masuk dari bagian atas dan keluar dari bagian bawah (Ismi 2006).

\section{Pemasaran}

Pasar domestik meliputi daerahdaerah potensi budidaya kerapu diantaranya: Bali, Jawa timur, Jawa Tengah, Jawa Barat; Padang, Lampung, 
Batam, Medan, Aceh, Balikpapan, memasarkan benih keperluan sekitarnya Bontang, dan lain-lain. Pasar ekspor dan daerah lain di Indonesia juga diantaranya Singapura, Malaysia, melakukan ekspor. Pada umumnya Brunei, Thailand, Filipina dan Vietnam. benih benih yang berukuran kecil $(\leq 10$ Enam pengusaha yang $\mathrm{cm}$ ) dikirimkan ke lokasi yang jauh mempunyai ijin ekspor, selain untuk meggunakan pesawat, sedangkan benih

Tabel 2. Perkiraan Analisis Usaha Pembenihan Kerapu Cantang dan Cantik dalam satu siklus.

\begin{tabular}{lcc}
\hline \multicolumn{1}{c}{ Uraian } & \multicolumn{2}{c}{ Jenis kerapu } \\
& Kerapu cantang & Kerapu cantik \\
\hline Jumlah telur (btr) & 200.000 & 200.000 \\
Daya tetas telur (\%) & 73,1 & 75,2 \\
Kelangsungan hidup(\%) & 20,5 & 19,2 \\
Harga telur.butir ${ }^{-1}(\mathrm{Rp})$ & 15 & 10 \\
Harga benih 3 cm (Rp.) & 2.200 & 2.000 \\
Biaya operasional (Rp) & 40.249 .600 & 36.049 .600 \\
Penjualan (Rp) & 63.958 .114 & 56.020 .992 \\
Keuntungan (Rp) & 23.709 .114 & 19.971 .392 \\
R/C rasio & 1,59 & 1,55 \\
\hline
\end{tabular}

Tabel 3. Perkiraan Analisis Usaha Pendederan benih ikan kerapu cantang dengan awal ukuran yang berbeda selama 30 hari.

\begin{tabular}{lrrr}
\hline \multicolumn{4}{c}{ Ukuran awal benih } \\
\hline & A. $\mathbf{\pm 3 , 0} \mathbf{~ c m}$ & B. $\mathbf{\pm 5 , 0} \mathbf{~ c m}$ & C. $\mathbf{\pm 7 , 0} \mathbf{~ c m}$ \\
\hline Benih (-3\%) & 20.370 .000 & 31.525 .000 & 44.135 .000 \\
Pakan,listrik, tenaga dan lain-lain & 6.150 .000 & 6.200 .000 & 6.440 .000 \\
\hline Jumlah operasional & 26.520 .000 & 37.725 .000 & 50.575 .000 \\
\hline Penjualan : diskon (-3\%) & & & \\
Harga (ekor) & 4.550 & 5.850 & 7.150 \\
A. SR (80,4\%) & 35.485 .450 & & \\
B. SR (87,9\%) & & 44.335 .200 & \\
C. SR (90,1\%) & & & 57.310 .500 \\
\hline Keuntungan & 9.465 .450 & 7.110 .200 & 6.235 .500 \\
Biaya (Rp.ekor ${ }^{-1}$ ) & 3.335 & 4.365 & 5.795 \\
Titik impas SR (\%) & $57.19 \%$ & $71,59 \%$ & 1,13 \\
R/C rasio & 1,34 & 1,18 & \\
\hline
\end{tabular}


yang berukuran besar $(\geq 14)$ digunakan untuk budidaya yang lokasinya dekat sumber benih mereka.

Empat pengusaha yang tidak mempunyai ijin untuk ekspor, memasarkan benih berukuran sekitar 2,7 $\mathrm{cm}$ dan hasil pendederan dengan ukuran tertentu (5,0 cm keatas) ke pengusaha di sekitarnya atau dikirim ke daerah lain di Indonesia.

Harga benih berfluktuasi tergantung waktu dan stok benih. Pada umumnya benih ikan kerapu catang mulai dijual saat berukuran $2,7 \mathrm{~cm}$ dengan harga Rp. 2000-3500 ekor ${ }^{-1}$ dan Rp. 1500-2500 ekor ${ }^{-1}$ untuk kerapu cantik. Perkiraan analisis usaha dari produksi benih ikan kerapu cantang dan cantik dalam satu siklus pembenihan (sekitar 40 hari) dapat dilihat pada Tabel 2.

Dari perkiraan analisis usaha dapat dilihat $R / C$ rasio $\geq 1,0$ dengan demikian pengusaha benih dari pembenihan sendiri masih menguntungkan, selain itu jika benih berasal dari pembenihan sendiri sudah pasti terjamin kualitas dan jumlahnya. Karena kebutuhan benih belum bisa terpenuhi dari hasil benih sendiri maka pengusaha membeli dari pengusaha yang lain. Jika sarana mencukupi, untuk memperoleh keuntungan lebih besar biasanya mereka membeli dengan ukuran kecil untuk dibesarkan lagi sesuai permintaan.
Untuk menambah keuntungan dan menyiapkan ukuran benih sesuai permintaan, banyak pengusaha memelihara kembali benih (didederkan). Harga benih setelah ukuran $4,0 \mathrm{~cm}$ tergantung pada ukuran panjang benih. Harga benih ikan kerapu cantang $R p$ 600-800 $\mathrm{cm}^{-1}$ dan harga benih kerapu cantik Rp. $500-700$ cm${ }^{-1}$. Perkiraan analisis usaha pendederan benih ikan kerapu cantang dengan ukuran awal berbeda yang dipelihara selama 30 hari, disajikan pada Tabel 3.

Hasil analisis usaha pada benih awal berukuran lebih kecil memperlihatkan bahwa usaha ini mempunyai keuntungan yang lebih besar, walaupun hasil kelangsungan hidupnya lebih kecil (dapat dilihat pada Tabel 3.). Hal ini disebabkan, harga benih awal yang dipelihara dari ukuran kecil lebih murah, jumlah pakan yang dikonsumsi lebih sedikit pada waktu pemeliharaan yang sama. Kegiatan ini memiliki kelangsungan hidup $80,40 \%$ dengan titik impas $57,19 \%, \mathrm{R} / \mathrm{C}$ rasio $=$ 1,34. Hasil ini lebih besar jika dibandingkan dengan usaha yang menggunaan benih awal yang lebih besar.

Jika benih yang dibeli oleh pengusaha langsung dikirim, maka harga benih merupakan kesepakatan penjual dengan pembeli. Harga benih di tempat 
asal rata-rata sama mengikuti fluktuasi harga, ditambah biaya pengiriman meliputi biaya dokumen, pengemasan, transportasi (darat, laut dan udara). Agar benih sampai di tujuan dengan selamat dan sehat, pengelolaan transportasi disesuaikan dengan jenis ikan, ukuran dan jarak tempuh sehingga mempengaruhi biaya yang akan dibebankan pada harga benih ikan.

\section{Kendala}

Jika benih berasal dari pembenihan sendiri, jumlah panen tidak pasti. Hal tersebut dikarenakan hasil pembenihan sangat tergantung pada kualitas telur yang merupakan salah satu kunci keberhasilan dalam usaha pembenihan (Ismi 2010, 2017). Saat musim penghujan, mendung, intensitas cahaya matahari berkurang, fitoplankton (Nannochloropsis sp.) tidak bisa berkembang sehingga persediaan pakan untuk rotifera berkurang. Suhu air laut yang rendah $\left(\leq 27^{\circ} \mathrm{C}\right)$, fluktuasi suhu harian yang tinggi $\left(\geq 2{ }^{\circ} \mathrm{C}\right)$ juga mempengaruhi kelangsungan hidup, sehingga benih ikan kerapu yang didapat hanya sedikit. Untuk memenuhi permintaan pasar benih harus dibeli dari unit pembenihan dan pendederan yang lain.

Kendala pada pendederan adalah pada saat-saat tertentu terjadi pasang surut laut yang tinggi, ombak besar, keruh dan berlumpur. Akibatnya banyak partikel-partikel kecil/lumpur yang lolos dan menyumbat saringan pasir yang membuat saringan pasir tidak lagi efektif. Air yang masuk dalam bak pendederan kotor sehingga benih di bak pendederan terganggu. Pada kondisi seperti ini, biasanya muncul penyakit dari bakteri seperti warna merah pada mulut. dan sirip. Jika tidak segera ditanggulangi badan akan luka dan banyak terjadi kematian (Ismi, Asih, et al. 2012).

Kendala pada transportasi adalah mahalnya biaya ransportasi, kematian benih karena tidak tepatnya penanganan, dan mundurnya jadwal penerbangan yang berakibat benih terlambat tiba di tujuan. Seharusnya benih sampai tujuan tepat jumlah, ukuran dengan kondisi sehat dan kualitas bagus, sehingga pembeli akan membayar sesuai kesepakatan.

\section{SIMPULAN}

Untuk memenuhi kebutuhaan pasar, pengusaha memperoleh benih ikan kerapu cantang dan cantik dari pembenihan sendiri dan membeli di tempat lain untuk didederkan atau langsung dijual. Benih ikan kerapu yang dipanen atau dibeli pada ukuran $\pm 2,75$ cm akan dipelihara lagi pada pendederan sampai ukuran sesuai permintaan pasar. Benih dipasarkan di dalam negeri dan luar negeri ke beberapa negera antara 
lain Singapura, Malaysia, Brunei, Thailand, Filipina, dan Vietnam.

Harga benih ikan kerapu ditentukan berdasarkan panjang total. Keuntungan terbesar diperoleh apabila pegusaha mendederkan benih dari ukuran kecil yaitu mulai $\pm 2,75 \mathrm{~cm}$ karena benih ukuran kecil memiliki harga yang lebih murah, dan membutuhkan biaya pakan yang lebih rendah.

\section{PERSANTUNAN}

Ucapan terima kasih kepada para pegusaha benih ikan kerapu di Kecamatan Gerokgak, Kabupaten Buleleng-Bali yang terlibat pada penelitian ini atas peran sertanya dan bantuannya sehingga penelitian ini selesai.

\section{DAFTAR PUSTAKA}

Giri, I. Nyoman Adiasmara. 2001. "Pembenihan ikan kerapu batik (Epinephelus microdon) sebagai upaya penyediaan benih untuk pengembangan budidaya laut." Warta penelitian perikanan Indonesia 7(1):3.

Heerin, S. V. 2002. "Technology transferbackyard hatcheries bring jobs, growth to Bali." Global Aquaculture Advocate 5:90-92.

Ismi, S. 2010. "Grouper hatchery business empowerment for coastal community. Dalam: Sudaryono et al." Hal. 1147-50 in Proceeding International Conference of Aquaculture Indonesia (ICAI) and International Conference on Shrimp Aquaculture (ICOSA).

Ismi, S., Y. N. Asih, D. Kusumawati, dan T. H. Prihadi. 2012. "Pendederan benih kerapu sebagai usaha untuk meningkatkan pendapatan masyarakat pesisir." Hal. 29-30 in Dalam: Karmiadji et al.,(eds.). Prosiding Seminar Insentif Riset SINas (INSINas 2012). Bandung. Ismi, S., T. Sutarmat, N. A. Giri, M. A. Rimmer, R. M. J. Knuckey, A. C. Berding, dan K. Sugama. 2012. Nursery Management of Grouper: A Best-Practice Manual. Canberra $(\mathrm{AU})$ : Australian Centre for International Agricultural Research (ACIAR).

Ismi, Suko. 2006. "Usaha pendederan benih kerapu macan (Epinephelus fuscoguttatus)." Media Akuakultur 1(3):97-101.

Ismi, Suko. 2017. "Produksi Telur Ikan Kerapu Hibrida Untuk Menunjang Usaha Pembenihan." Jurnal IImu dan Teknologi Kelautan Tropis 9(2):783-94.

Ismi, Suko dan Yasmina Nirmala Asih. 2011a.

"Pengamatan perkembangan benih kerapu hybrid persilangan antara kerapu macan (Epinephelus fuscoguttatus), 
kertang (Epinephelus lanceolatus)." Hal. 100-104 in Prosiding Seminar Nasional Kelautan VII. Universitas Hang Tuah, Surabaya. Vol. 20.

Ismi, Suko dan Yasmina Nirmala Asih. 2011b. "Perkembangan telur dan tingkah laku larva kerapu hybrid cantang." Hal. 9-12 in Prosiding FORUM INOVASI TEKNOLOGI AKUAKULTUR. Vol. 1.

Ismi, Suko, Yasmina Nirmala Asih, dan Daniar Kusumawati. 2013. "Peningkatan produksi dan kualitas benih ikan kerapu melalui program hibridisasi." J. Ilmu dan Teknologi Kelautan Tropis 5(2):333-42.

KKP. 2008. Pedoman Umum Cara Pembenihan Ikan yang Baik (CPIB). Jakarta (ID): Departemen Kelautan dan Perikanan Direktorat Jendral Perikanan Budidaya Direktorat Pembenihan.

Rimmer, M. A., A. Bride, dan K. C. William. 2004. "Advances in grouper aquaculture. ACIAR Monograph. No. 110." Australian Center for International Agriculture Research Canberra.

Siar, Susana V, William Lee Johnston, dan Sih Yang Sim. 2001. Study on economics and socio-economics of small-scale marine fish hatcheries and nurseries, with special reference to grouper systems in Bali, Indonesia. Vol. 1. Bangkok
(TH).

Soekartawi. 1991. Teori ekonomi produksi dengan pokok bahasan analisa fungsi. diedit oleh C. Douglass. Jakarta (ID): Raja Gafindo Persada.

Soekartawi. 2001. Agribisnis teori dan aplikasinya. Jakarta (ID): Raja Grafindo Persada.

Sugama, K., M. A. Rimmer, S. Ismi, I. Koesharyani, K. Suwirya, N. A. Giri, dan V. R. Alava. 2012. Hatchery Management of Tiger Grouper (Epinephelus Fuscoguttatus): $A$ Best-Practice Manual. Canberra $(\mathrm{AU})$ : Australian Centre for International Agricultural Research (ACIAR). 